\title{
INSCRIPCIONES HONORÍFICAS DEL TEATRO ROMANO DE CARTAGENA. ADDENDUM A AEspA 1992
}

POR

\author{
SEBASTIÁN F. RAMALLO ASENSIO \\ Universidad de Murcia
}

La inscripción objeto de la presente nota complementa un artículo anterior ${ }^{1}$ y convierte el teatro romano de Cartagena en el monumento con el programa epigráfico más completo y mejor definido de la ciudad, al tiempo que refuerza la hipótesis de una intervención directa de miembros de la familia imperial y de su círculo más inmediato en la financiación de este monumental edificio.

El hallazgo, escalonado en las campañas de 1995 y 1996, se produjo al excavar el relleno de una gran fosa de expolio de época preislámica situada junto al aditus oriental. El fragmento de mayores dimensiones (L.Ca), hallado en julio de 1996, conservaba aún trazas del muro de opus vittatum del complejo comercial de la segunda mitad del siglo v en cuya cimentación había sido englobado todo el dintel ${ }^{2}$.

\footnotetext{
${ }^{1}$ Ramallo Asensio, S. F., «Inscripciones honoríficas del teatro de Carthago Nova», AEspA, 65, 1992, 49-73. Corresponden al dintel del aditus occidental donde restituimos el texto [C(aio) Caes]ari Augustif(ilio) divi n(epoti) y a dos arae con los epígrafes respectivamente L(ucius) Iunius L(ucii) f(ilius) T(iti) n(epos) / Paetus / Fortunae sac(rum) d(onum) $d$ (edicavit) y en la segunda, C(aii) Caesaris Augusti f(ilii) / pontif(icis) $\operatorname{co}(n) s($ ulis) desig(nati) / principis iuuentutis / [L(ucius) Iu]nius L(ucii) f(ilius) T(iti) n(epos) Paetus [sac(rum)] d(onum) d(edicavit). Es interesante añadir respecto al dedicante, $L$. Iunius Paetus, el hallazgo de un fragmento de inscripción en travertino rojo descubierto en las excavaciones del Molinete, precisamente en una zona que se interpreta como restos de un posible capitolium (vid. B. Roldán y L. de Miquel, «Excavaciones en el Cerro del Molinete (Cartagena)», Revista de Arqueología, 184, 1996, 56-57), mientras que el cognomen Paetus, quizás el mismo L. Iunius, aparece sobre un fragmento de inscripción conservado en uno de los muros de cimentación de la Catedral Vieja, superpuesto a las galerías de sustentación del graderío del teatro. Estos datos sugieren que nos hallamos ante una importante familia de época augustea, hasta ahora no considerada, con una destacada proyección desde el punto de vista evergético. Vid. ahora para las llamadas «grandes familias», M. Koch, «Die römische Gesellschaft von Carthago Nova nach den epigraphischen Quellen», Festschrift J. Untermann, Innsbruck, 1993, especialmente 215-220. A estas inscripciones habría que añadir también una placa de caliza gris con una I entre dos interpunciones triangulares que probablemente formaba parte de la dedicación con letras de bronce dorado situada frente a la orchestra.

${ }^{2}$ Un primer análisis de este complejo en Ramallo Asensio, S., San Martín Moro, P.A. y Ruiz Valderas, E.: «Teatro romano de Cartagena. Una aproximación preliminar», Cuadernos de Arquitectura Romana, 2, 1993, 51-92.
}

Mide $88 \mathrm{~cm}$ de altura x $114 \mathrm{~cm}$ de ancho y $54 \mathrm{~cm}$ de grosor (44 $\mathrm{cm}$ en la cartela), mientras que el texto restante se conserva en 15 piezas de distinto tamaño, a las que hay que añadir otras 15 más sin texto.

Previsiblemente la anchura total del dintel debió ser de 4,30 m, mientras que el vano que cubría, señalado en el suelo por un umbral de mármol, tiene una anchura de $2,70 \mathrm{~m}$. El texto, que podemos restituir como L(ucio) Caesari Augusti f(ilio) divi $n$ (epoti), se inscribe en una cartela rectangular de 37 $\mathrm{cm}$ de alto delimitada por una doble moldura. La letra es capital cuadrada de excelente factura y surco profundo de perfil en V, bien biselado; mide 18,5 cm excepto la T de Augusti y las dos I longae de divi que miden $21,5 \mathrm{~cm}$. La parte alta del sillar está rematada con una moldura formada por un ancho listel, cyma recta y listel, mientras que la inferior es completamente lisa. A los lados flanquean la inscripción dos cuerpos rectangulares lisos de 46 x 88 $\mathrm{cm}$ (fig. 1).

Si aceptamos la identificación de Caius en la inscripción del aditus occidental hallada en 1990, nos encontraríamos en los dos ingresos monumentales de la parte baja del teatro, y en uno de sus lugares preeminentes, con sendos epígrafes dedicados a los dos nietos y herederos de Augusto, al igual que, en el año 16 a. C., se habían colocado dinteles similares en el teatro de Mérida en honor de su padre M. Vipsanius Agrippa, como impulsor de la obra (CIL, II, 474).

En cuanto a los dos muchachos, Caio y Lucio, hijos de Agrippa y Julia, nacen respectivamente en los años 20 y 17 a.C. y fueron adoptados por Augusto en el año 17 a.C. Lucio, el más joven de ambos, que muere el 20 de agosto del año 2 d. C. en Marsella, a los 19 años, pocos días después de haber embarcado en Roma con destino a Hispania ${ }^{3}$, fue augur ${ }^{4}$, princeps iuventutis y consul designatus en

3 Vid. en general, RE, s. v. Iulius (Caesar), $\mathrm{n}^{\circ}$ 145, col. 472-473. PIR, pars IV, fasc. 3, s.v. L. Iulius Caesar, $\mathrm{n}^{\circ} 222$, pp. 185-187.

${ }_{4}$ CIL, V, 6416, inscripción del arco Ticiensis de Pavía, L(ucio) Caesari Augusti f(ilio) divi nepot(i) auguri 

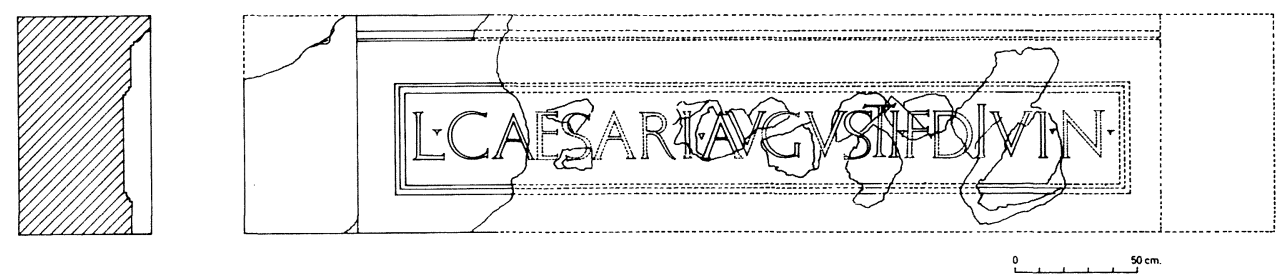

Fig. 1.

el año 2 a. C., magistratura que no llegó a desempeñar de forma efectiva por su muerte prematura. Caio, consul designatus en el año 5 a.C., fue consul en el 1 d.C. e imperator en el año 3 d.C. y murió en Limyna (Lycia) el 21 de febrero del año $4{ }^{5}$. La rápida promoción pública de ambos personajes, pese a su juventud, y la idea de sucesión dinástica expresada de forma manifiesta en las emisiones monetales de Lyon, encuentra su máxima expresión en la dedicación, junto a su padre adoptivo, del templo de Mars Ultor ${ }^{6}$ y se manifiesta además en la amplia actividad evergética y edilicia iniciada por el propio Augusto y completada por los dos jóvenes príncipes, ensalzados, al igual que su padre M. Agrippa en varias ciudades hispanas ${ }^{7}$. Sus retratos o imágenes aparecen en los reversos monetales de las cecas de Gades, Iulia Traducta, Tarraco y Caesaraugusta ${ }^{8}$.

En consecuencia, ambos personajes, estrechamente vinculados a la figura de Augusto desde el año 6 a. C. ${ }^{9}$, aparecen frecuentemente ligados en dedicaciones gemelas, como por ejemplo en dos

co(n)s(uli) design(ato) principi iuventutis. Vid. también CIL, VI, 898, CIL, II, 2109, CIL, V, 2067, y el conocido decreto de Pisa, CIL, XI, 1420. Vid." también, Hanson, C. y Johnson, F., «On certain portrait inscriptions», AJA, 50,3, 1946, 396397.

5 RE, s.v. Iulius, $\mathrm{n}^{\circ} 134$, col. 424, y también PIR, ii, p. $174, \mathrm{n}^{\circ} 141$. Para el cenotafio de Lycia, vid. Borchardt, J., en JDAI, 89, 1974, 217 ss. y Ganzert, J., Das Kenotaph für Gaius Caesar im Limra, Ist.Forsch., 35, 1984.

6 Alföldy, G., «L'iscrizione dedicatoria del tempio di Mars Ultor», Studi sull'epigrafia augustea e tiberiana di Roma, Roma, 1992, 17-32.

7 Por la epigrafía, sabemos que Caio fue patrono de las ciudades de Rusellae, Salaria (Úbeda la Vieja), Ulia y probablemente de Nemausus; Lucio, por su parte, fue patrono de Pisa y de Cosa. Vid. en esta misma línea, Canto, A. M ${ }^{\mathrm{a}}$., «Colonia Patricia Corduba: nuevas hipótesis sobre su fundación y nombre», Latomus, L, 4, 1991, especialmente, 852 y 854.

8 Vid. respectivamente: Gades, $R P C$, 97-98; Iulia Traducta, $R P C, 101-107$; Tarraco, $R P C, 210-214$ y Caesaraugusta, $R P C, 323-324$.

9 Según R. Etienne, Le culte impérial dans la Peninsule Ibérique d'Auguste à Diocletien, París, 1958, p. 397, a la muerte de Agrippa (12 a.C.) desaparece Tiberio de las dedicaciones y los nietos Caio y Lucio reciben todos los homenajes entre el 6 a.C. y el 4 d. C. Vid. también, C. H. V. Sutherland, "Aspects of imperialism in Roman Spain», JRS, XXIV, 1934, 35. Zanker, P., Augusto y el poder de las imágenes, Madrid, 1992, 255-265. basas iguales halladas en el Foro Boario, dedicadas entre los años 2 y 1 a. C. a juzgar por el cursus que presentan ambos muchachos ${ }^{10}$, o las halladas en el agro Viterbiensi ${ }^{11}$, donde Lucio aparece sólo como Aug(usti) f(ilio) divi nep(oti), mientras que Caio presenta ya el título de pontifex y el de consul designatus, lo que lleva a fechar la inscripción entre los años 4-3 a. C.

En la península ibérica han aparecido otras dedicaciones a Lucio en Mentesa (CIL, II, 2109), Montoro (CIL. II, 2157), Bracara (CIL, II, 2422) y con lecturas inciertas, aunque muy plausibles, en Alcolea del Río (CIL, II, 1063) y Ampurias ${ }^{12}$, y testimonian el amplio favor que gozó junto a su hermano en los pocos años que precedieron su muerte tras la adopción oficial por Augusto.

La inscripción de Cartagena incorpora, como ya era de esperar tras los hallazgos de 1990, un nuevo personaje a la nómina de personalidades ilustres que, vinculadas por sangre o amistad con el propio Augusto, son distinguidas con las más altas magistraturras de la ciudad. Esta serie que comienza por el propio emperador, IIvir quinq. junto a Agrippa, probablemente en torno al año 12-11 a. C. ${ }^{13}$, sigue con Tiberio Claudio Nero, patrono según una inscripción reutilizada en uno de los muros del Castillo de la Concepción ${ }^{14}$ y IIvir quinq. en época de Augusto ${ }^{15}$, y con el mismo Agrippa, asimismo nom-

${ }^{10}$ ILS, 131 y 132, CIL, VI, 897-898.

1 ILS, 106 = CIL, XI, 1, 3040.

12 Bonneville, J. N., «Les patrons du municipe d'Emporiae (Ampurias, Espagne)», Hommage R. Etienne, París, 1988, 191, $\mathrm{n}^{\circ} 7$, puede ser Caio o Lucio.

${ }_{13}$ Magistratura que fue desempeñada por sus praefecti $\mathrm{L}$. Bennius y Q. Varius Hiberus, respectivamente, vid. Llorens, M. del Mar, La ciudad de Carthago Nova: las emisiones romanas, Murcia, 1994, emisión n X, 59-61. Curchin, L. A., The Local Magistrates of Roman Spain, Toronto, 1990, ubica ambos magistrados, y en consecuencia la emisión, entre los años 18 y 12 a.C., vid. p. 194, nº 558 y 559. En la colección epigráfica no tenemos constancia de actividad edilicia de estos personajes; sí aparecen, en cambio, textos incompletos de algún magistrado con cognomen Pollio, aunque su relación con el praefecto, de Ti. Claudio Nero, C. Helvius Pollio, no se puede determinar (cfr. para la inscripciones CIL, II, 3429 y 3430 ).

${ }^{14}$ CIL, II, 5930, = EE 3, 33.

$15 R P C, 166$, Llorens, op. cit. (n. 13), 62-63. 
brado patrono en torno a los años 19-18 a. C., además de IIvir quinq., como ya se ha señalado ${ }^{16}$, y se completa, hasta el momento, con P. Silius Nerva, personaje muy vinculado al general, cónsul en el año 20 a. C., legatus Augusti pro praetore de la Citerior entre los años 19 y 16 a. C., y patrono de la ciudad por esos años ${ }^{17}$. Esta vinculación de la ciudad con los jóvenes príncipes de la familia imperial no termina con los nietos de Augusto, sino que se manifiesta de nuevo años más tarde en las emisiones de Tiberio con reverso de Nerón y Druso como IIviri quinquennales, adoptados por el emperador en el año 23 tras la muerte de su hijo Druso ${ }^{18}$. El grado de compromiso de todos ellos y su aportación en el amplio y precoz proceso de renovación urbanística y monumentalización que se produce en la ciudad durante estos años, y del cual el teatro es hasta ahora el ejemplo más significativo, es aún muy difícil de valorar. Sin embargo, es muy interesante destacar, a este respecto, la estrecha similitud estilística de los capiteles y de los elementos arquitectónicos del teatro de Cartagena con los de la ciudad africana de Cherchel ${ }^{19}$, producto probablemente en ambos casos de talleres procedentes de la propia Roma. Esta coincidencia es aún más interesante si consideramos que la construcción del teatro de Cherchel ${ }^{20}$ fue promovida por el rey Iuba II, a su vez IIvir quinq. y patrono de la ciudad hispana, y que en ambos casos la selección de este edificio como espejo de la nueva arquitectura de prestigio representa una ruptura con toda la tradición arquitectónica anterior cimentada sobre los órdenes jónico y tuscánico. La incidencia de este patronazgo sobre la renovación urbanística de la ciudad no se

16 Koch, M., "Agrippa und Neukarthago», Chiron 9, 1979, 205-214, inscripción hallada en 1926 durante los trabajos de urbanización del Castillo de la Concepción, donde actualmente se conserva empotrada en el machón central de la Torre de Alfonso X. Vid. Koch, op. cit. (n. 1), 213, y también Roddaz, J. M., Marcus Agrippa, BEFAR, 253, Roma, 1984, p. 414, nota 139, así como Roddaz, J. M., «Agrippa y la Península Ibérica», Anas, 6, 1993, 116-126. Para la emisión monetal, Llorens, op. cit. (n. 13), n X, 59-61.

17 CIL II 3414. Sobre el personaje, vid. Alföldy, G., Fasti Hispanienses, Wiesbaden, 1969, p. 7.; RE, s.v. Silius, $\mathrm{n}^{\circ} 21$.

${ }_{18}$ La emisión $n^{\circ}$ XVII ha sido fechada en el año $27 / 28$, en función del paralelismo de esta emisión con otra similar de Útica datada en estos mismos años, vid. Llorens, op. cit. (n. 13), 74-75.

${ }_{19}$ Pensabene, P., Les chapiteaux de Cherchel. Étude de la décoration architectonique, 3 suppl. Bull. d'Archeologie Algerienne, 1982, y Pensabene, P., «La decorazione architettonica di Cherchel: cornici, architravi, soffitti, basi e pilastri», $\operatorname{MDAI}(R)$, Erg. 25, 1982, especialmente 119-120.

20 Ver para la fecha de construcción, Picard, G., «La date du théâtre de Cherchel et les débuts de l'architecture théâtrale dans les provinces romaines d'Occident», CRAI, 1975, 386-397. puede, de momento, determinar, y tampoco si existe una mayor relación, más allá de la meramente estilística y de procedencia común en los modelos utilizados para los elementos arquitectónicos. Por lo demás, la relación con el puerto mauritano de Cesarea (Cherchel), transmitida por los textos ${ }^{21}$, se constata arqueológicamente a finales del siglo II o inicios del i a.C., con el hallazgo de lingotes de plomo con el sello Q. Varius Hiberus procedentes de la ciudad hispana, lo que nos hace intuir también la existencia de intereses comerciales entre ambas ciudades que en gran medida podrían también justificar la promoción, años más tarde, de Iuba II y de su hijo Ptolomeo a las más altas magistraturas de la ciudad.

Finalmente, la inscripción hallada ahora sobre el aditus oriental sirve para reafirmar aún más la cronología propuesta para el teatro, a partir sobre todo del ara de C. Caesar y de los rasgos estilísticos de los capiteles, y costriñe la fecha de dedicación del edificio a un momento anterior al año $2 \mathrm{~d}$. C., data de la desaparición del joven princeps, al tiempo que confirma su intervención junto a su hermano. Incluso, dada la ausencia de cualquier título sobre el dintel, se podría proponer una fecha en torno a los años 4-3 a. C., que coincidiría plenamente con la que se deduce del ara de Caio y con numerosos detalles estilísticos del programa arquitectónico y ornamental.

En cualquier caso, el teatro de Cartagena, en su papel de «lugar de encuentro entre el monarca y el pueblo» ${ }^{22}$, se configura como uno de los ejemplos más tempranos de la utilización de estos grandes monumentos públicos, y concretamente de los programas epigráficos e iconográficos en ellos contenidos, en la transmisión de la nuevas ideas de sucesión dinástica y promoción pública de los herederos, al tiempo que se presenta como un preludio de los edificios destinados al culto imperial que muy pronto se desarrollarán en torno o en el propio teatro ${ }^{23}$.

21 Vid. en general, González Cravioto, E., «Relaciones comerciales entre Carthago Nova y Mauritania durante el Principado de Augusto», AUM, XL (3-4), 1981-82, 13-26.

22 Parafraseando a Zanker, op. cit. (n. 9), 181.

23 Vid. para la función de los teatros como vehículo de difusión del culto imperial, Gros, P., «Théâtre et culte impérial en Gaule Narbonnaise et dans la Péninsule Ibérique», Stadtbild und Ideologie, Madrid, 1987 (München, 1990), 381-390, donde se analizan los ejemplos más significativos y se puede localizar la bibliografía esencial sobre el tema. 